BMJ Nutrition, Prevention \& Health \title{
and blood pressure in the INTERMAP study \\ Association between plant-based diets
}

Ghadeer Aljuraiban (D , ,,2 Queenie Chan, ${ }^{2,3}$ Rachel Gibson, ${ }^{2,4}$ Jeremiah Stamler, ${ }^{5}$ Martha L Daviglus, ${ }^{6}$ Alan R Dyer, ${ }^{5}$ Katsuyuki Miura, ${ }^{7}$ Yangfeng Wu, ${ }^{8}$ Hirotsugu Ueshima, ${ }^{7}$ Liancheng Zhao, ${ }^{9}$ Linda Van Horn, ${ }^{5}$ Paul Elliott, ${ }^{2,3}$ Linda M Oude Griep, ${ }^{2,10}$ for the INTERMAP Research Group

To cite: Aljuraiban G, Chan Q, Gibson $\mathrm{R}$, et al. Association between plant-based diets and blood pressure in the INTERMAP study. BMJ Nutrition, Prevention \& Health 2020;3:e000077. doi:10.1136/ bmjnph-2020-000077

- Additional material is published online only. To view please visit the journal online (http://dx.doi.org/10.1136/ bmjnph-2020-000077).

For numbered affiliations see end of article.

Correspondence to Ghadeer Aljuraiban, Department of Community Health Sciences, College of Applied Medical Sciences, King Saud University, Riyadh, Saudi Arabia; galjuraiban@ksu.edu.sa

Received 31 March 2020 Revised 14 May 2020 Accepted 28 May 2020 Published Online First 8 July 2020

Check for updates

(c) Author(s) (or their employer(s)) 2020. Re-use permitted under CC BY-NC. No commercial re-use. See rights and permissions. Published by BMJ.

\section{ABSTRACT}

Background Plant-based diets are associated with a lower risk of cardiovascular diseases; however, little is known how the healthiness of the diet may be associated with blood pressure (BP). We aimed to modify three plant -based diet indices: overall plant-based diet index (PDI), healthy PDI (hPDI), and unhealthy PDI (uPDI) according to country-specific dietary guidelines to enable use across populations with diverse dietary patterns - and assessed their associations with BP.

Design We used cross-sectional data including 4,680 men and women ages 40-59y in Japan, China, the United Kingdom, and the United States from the INTERnational study on MAcro/micronutrients and blood Pressure (INTERMAP). During four visits, eight BP measurements, and four 24-h dietary recalls were collected. Multivariable regression coefficients were estimated, pooled, weighted, and adjusted extensively for lifestyle/dietary confounders. Results Modified PDI was not associated with BP. Consumption of hPDI higher by $1 \mathrm{SD}$ was inversely associated with systolic $(-0.82 \mathrm{~mm} \mathrm{Hg} ; 95 \% \mathrm{Cl}$ - 1.32 ,0.49 ) and diastolic BP (-0.49 mm Hg; $95 \%$ Cl:-0.91, -0.28). In contrast, consumption of an uPDI was directly associated with systolic $(0.77 \mathrm{~mm} \mathrm{Hg} ; 95 \% \mathrm{Cl}: 0.30,1.20)$. Significant associations between hPDI with BP were attenuated with separate adjustment for vegetables and whole grains; associations between UPDI and BP were attenuated after adjustment for refined grains, sugarsweetened beverages, and meat.

Conclusion An hPDI is associated with lower BP while a uPDI is adversely related to BP. Plant-based diets rich in vegetables and whole grains and limited in refined grains, sugar-sweetened beverages, and total meat may contribute to these associations. In addition to current guidelines, the nutritional quality of consumed plant foods is as important as limiting animal-based components. Trial registration number The observational INTERMAP study was registered at www.clinicaltrials.gov as NCT00005271.

\section{INTRODUCTION}

Consumption of a plant-based diet, with little or no animal-based foods, has been associated with a lower risk of cardiovascular diseases. ${ }^{1}$ A plant-based dietary pattern encourages
What this paper adds?

- Higher adherence to a high quality plant-based diet, but not an overall plant-based diet, was inversely associated with systolic and diastolic BP.

- A higher score of an unhealthy plant-based diet was directly associated with systolic BP.

- Intakes of vegetables and whole grains explained the inverse associations of a healthy plant-based diet with BP, while intakes of refined grains, sugarsweetened beverages, and total meat contributed to the direct associations of an unhealthy plant-based diet with BP.

the intake of nutrient-dense plant foods like fruits, vegetables, whole grains and legumes while reducing processed and animal foods. ${ }^{2}$ Plant-based diets are rich in fibre, vitamins and polyphenols, potassium and unsaturated fatty acids, and low in saturated fatty acids and sodium, which help maintain healthy blood pressure (BP). ${ }^{34}$ The 2015 Dietary Guidelines Advisory Committee report recommends shifting to a plant-based diet and limiting intake from animal sources. ${ }^{5}$

Meta-analyses of randomised controlled trials and observational studies that evaluated the relationship between consumption of vegetarian versus omnivorous diets on $\mathrm{BP}$ showed inconsistent results. ${ }^{16}$ These inconsistent results may be explained by including and/or excluding animal sources as part of vegetarian diets and by differences in study populations and their dietary patterns. Moreover, previous investigations considered all plant foods healthy_even those associated with adverse health effects including refined grains and sugar-sweetened beverages. Satija $e t$ $a l^{7}$ addressed these limitations by creating an overall, graded plant-based diet index (PDI) differentiating a healthy PDI (hPDI) from an unhealthy PDI (uPDI). They observed inverse 
associations of the hPDI with the incidence of coronary heart disease (CHD), but direct associations for uPDI. ${ }^{7}$

To the best of our knowledge, limited available studies have simultaneously investigated the influence of the healthiness of a PDI relative to BP in diverse populations with large differences in dietary patterns. The application of the PDI to different populations is challenging: this includes equal weighting of food groups with low or no consumption in specific populations, lack of cut-offs for intakes of food groups, and use of food frequency questionnaires which, unlike multiple 24 hours dietary recalls, generally lack sufficient detail for assessing potential associations. Hence, we investigated cross-sectional associations with BP of the healthiness of the PDI, modified according to country-specific dietary guidelines for use across populations with diverse dietary patterns in the UK, the USA, Japan and China. We further identified which individual food groups contributed most to the reported associations. We used detailed multipass 24 hours dietary recalls and 24 hours urinary excretion data from the INTERnational study on MAcro/micronutrients and blood Pressure (INTERMAP) including 17 population samples.

\section{METHODS}

\section{Population samples and study design (1996-1999)}

The INTERMAP study is a cross-sectional investigation into the influence of dietary factors on BP. The sample included 4680 men and women aged 40-59 years from 17 population samples with a large variety of ethnic backgrounds in the UK, USA, Japan and China. ${ }^{8}$ The INTERMAP study initially surveyed 4895 adults. Excluded individuals were those who failed to attend all four study visits $(n=110)$, whose dietary data were unreliable $(n=7)$; whose total energy intake on any recall was $<500$ or $>5000 \mathrm{kcal} / \mathrm{d}$ (women) or $<500$ or $>8000 \mathrm{kcal} / \mathrm{d}$ (men) ( $\mathrm{n}=37$ total); or whose data were incomplete or missing, such as unrecorded urine samples and signalled a violation of protocol $(n=61)$. Hence, our study sample included 4680 participants (2359 men and 2321 women).

All data, dietary and non-dietary were collected subject to comprehensive quality controls including international, national and local monitoring to ensure compliance. ${ }^{9}$ All participants signed informed consent forms. At all sites, local institutional ethics committees approved the study.

\section{Dietary assessment}

Participants made four visits (two pairs) to their local field centre; each pair occurred on consecutive days, with an average interval of 3 weeks. At each visit, trained interviewers conducted an in-depth multipass 24 hours dietary recall using a standardised protocol to query participants on their food and beverage consumption over the past 24 hours, including dietary supplements. A single recall only describes food consumption of the reported day and may not be sufficient to describe participants' long-term usual intake; the average of four 24 hours dietary recalls was therefore used to estimate habitual daily dietary intake. ${ }^{10}$ Dietary recalls allow investigation of diverse dietary patterns and assessment of a person's entire dietary intake for a number of days. Country-specific aids such as food pictures, various types and sizes of containers and fresh foods of standardised portion size, were used to increase accuracy.

Recorded foods were coded and categorised into 18 food groups using the US Department of Agriculture (USDA) food coding scheme. ${ }^{11}$ To calculate the nutritional content of foods, we consulted country-specific food composition tables. ${ }^{8}$ Correlation coefficients between dietary and urinary $\mathrm{Na}$ and $\mathrm{K}$ were 0.42 and 0.55 , respectively, and 0.51 between dietary protein and urinary urea for all participants. ${ }^{9}$

\section{Plant-based diet indices}

The PDI designed by Satija $e t a l^{7}$ assigns positive scores to plant foods and reverse scores to animal foods, while the hPDI and uPDI differentiate in healthiness. The hPDI assigns positive scores to plant foods that are considered healthy based on recent systematic reviews and meta analyses $^{12-18}$ (whole grains, fruits, vegetables, nuts, legumes, vegetable oils and tea/coffee) and reverse scores to plant foods considered less healthy ${ }^{19-21}$ (fruit juices, sugarsweetened beverages, refined grains, potatoes and sweets and desserts) and animal foods (dairy products, eggs, fish or shellfish, total meat and miscellaneous foods, eg, hamburger). In contrast, the uPDI assigns positive scores to less healthy plant food groups and reverse scores to healthy plant food and animal food groups.

We modified the PDI, hPDI and uPDI according to country-specific dietary guidelines for use across populations with diverse dietary patterns (online supplementary table S1). We first categorised all reported foods into 18 food groups according to Satija $e t$ al. ${ }^{7}$ Out of the 18 food groups, 12 food groups (fruits, vegetables, legumes, vegetable oils, tea/coffee, refined grains, potatoes, sweets/ desserts, animal fat, eggs, total meat and miscellaneous foods) were consumed by all populations and no "nonconsumers' were identified. Per food group, participants with intakes equal or higher than country-specific recommendations were categorised into the highest quartile and were assigned the highest score of 4. Participants with intakes lower than country-specific recommendations were divided into tertiles of intake and were assigned scores 3 to 1 by descending tertiles. Countryspecific cut-offs were based on recommended intakes of the US Dietary Guidelines for Western participants ${ }^{5}$ and the Chinese Dietary Guidelines for East Asian participants. ${ }^{22}$ For example, Western participants consuming $\geq 2 \frac{1}{2}$ cups/day of vegetables (based on the US Dietary Guidelines) were assigned a score of $4(\mathrm{n}=500)$. The rest of the participants consuming $<2 \frac{1}{2}$ cups/day $(n=2196)$ were divided into tertiles of intake and were assigned scores 3 to 1 by descending tertiles. This resulted in four categories: $(\mathrm{n}=500),(\mathrm{n}=732), \quad(\mathrm{n}=732)$ and $(\mathrm{n}=732)$. 
While East Asian participants consuming $\geq 3$ cups/day of vegetables (based on the Chinese Dietary Guidelines) were assigned a score of $4(n=560)$. The rest of the participants $(\mathrm{n}=1424)$ consuming $<3 \mathrm{cups} /$ day were divided into tertiles of intake and were assigned scores 3 to 1 by descending tertiles, resulting in four categories: $(n=560)$, $(\mathrm{n}=474),(\mathrm{n}=475)$ and $(\mathrm{n}=475)$.

The remaining six food groups were consumed in low amounts (nuts, fish or shellfish, fruit juice, whole grains, dairy products and sugar-sweetened beverages) and scores were assigned based on consumed (score $=1$ ) or not consumed (score $=0$ ) to ensure comparability across the various population samples. For example, we found that the intake of dairy products was low in China, which did not allow dividing the amount into quartiles; therefore, we assigned (score $=1$ ) when consumed and (score $=0$ ) when not consumed. Online supplementary table S1 presents assignment of positive or reverse scores for each of the plant-based indices.

The 18 food group scores were summed to calculate the plant-based index scores. High scores on the three indices suggest a low intake of animal foods, but differ in healthiness. The maximum score for all scores is 54 and the minimum score is 12 .

\section{Measurement of blood pressure}

Trained staff used a random zero sphygmomanometer and measured BP eight times; two on each of the four visits in a quiet room. Participants emptied their bladders first and rested their feet flat on the floor for at least $5 \mathrm{~min}$ before measurement. ${ }^{8}$

\section{Assessment of confounding variables}

A questionnaire queried demographic characteristics (sex, age and ethnic group) and other possible confounding factors including education, occupation, physical activity, smoking, medical history, use of special diet, medication use, menopausal status and use of contraceptives or hormone replacement therapy. ${ }^{8}$ Each participant provided two timed 24 hours urinary samples. Body mass index (BMI) was calculated from four weight and height measurements made twice on the first of each pair of visits. Participants wore no shoes or heavy clothing during measurement. Data on alcoholic beverage intake over the past 7 days were collected at the first and third visits.

\section{Statistical methods}

We used SAS V.9.3 for all statistical analyses. Results of the four 24 hours dietary recalls were averaged to estimate habitual daily dietary intake $(\mathrm{g} / 1000 \mathrm{kcal})$. The average of eight BP measurements and mean urinary data across the two 24 hours urinary collections were used.

We present baseline characteristics of participants by quartiles of hPDI and uPDI. To assess the linearity of the investigated relations, we used a linear age-adjusted, gender-adjusted and population sample-adjusted model. Associations between the three indices were explored using partial Pearson correlation, adjusted for age, sex and population sample, pooled and weighted by country.

To determine reliability of PDIs, we used the following formula for the three PDIs calculated from the means of the two pairs of visits: $1 /[1+(\mathrm{ratio} / 2)] \mathrm{x} 100$, which divides the ratio of intraindividual variance by interparticipant variance. $^{23}$

Multivariable linear regression analyses examined associations of BP with PDI, hPDI and uPDI per $1 \mathrm{SD}$, which equals six points in scoring. This is equivalent to the following recommended healthy plant-based food groups: $1 / 4$ serving of whole grains, $1 / 3$ serving of fruits, 1 serving of vegetables, $1 / 4$ serving of nuts, $1 / 2$ serving of legumes, $1 / 2$ tsp of vegetable oil, 1/2 cup of tea/coffee and limits the following less healthy plant-based and animal food groups to: less than $1 / 4$ cup of fruit juice, 3 servings of refined grains, $1 / 4$ serving of potato, less than $1 / 4$ can of sugar-sweetened beverages, $1 / 2$ cupcake, 1 slice of cheese, $1 / 4$ of an egg, $1 / 4$ serving of fish or shellfish and total meat, 1/2 tsp of animal fat and 1/4 serving of miscellaneous foods.

We used two sequential models, adjusted extensively for potential lifestyle and dietary confounders, including alcohol, of the association of plant-based diet indices and BP. We included three additional models to investigate the roles of BMI, urinary sodium and potassium excretion. We also investigated which of the 18 food groups contributed most to the associations with $\mathrm{BP}$ using mutually adjusted isocaloric models and creating a variable that summed up the groups other than the variable of interest to avoid over adjustment (eg, when investigating the role of whole grains in the association between hPDI and BP, we created a variable that summed up food groups other than whole grains).

Models were fit by country and coefficients were pooled, weighted by the inverse of their variance. ${ }^{23}$ The $\chi^{2}$ test assessed the cross-country heterogeneity of regression coefficients. We also presented results by region due to differences in dietary patterns and lifestyle behaviours across different populations.

We repeated these analyses in subcohorts excluding participants with characteristics that might bias the association between hPDI and uPDI with BP, to investigate whether the main findings were independent of characteristics such as hypertension, antihypertensive drug use, prevalent major chronic diseases: a subcohort excluding participants with self-reported diagnosis of hypertension and users of antihypertensive drugs $(\mathrm{n}=3532)$, a subcohort excluding hypertensive participants $(\mathrm{n}=3363)$ and a subcohort excluding those with prevalent major chronic diseases $(n=3051)$. Additionally, we repeated the analysis in a subcohort of users of antihypertensive drugs $(n=1148)$ and a subcohort of participants diagnosed with diabetes $(n=277)$. Sensitivity analysis was also done for scores based only on the 12 food groups consumed in all countries (fruits, vegetables, legumes, vegetable oils, tea/ coffee, refined grains, potatoes, sweets/desserts, animal fat, eggs, total meat and miscellaneous foods $)(n=4,680)$ 
to investigate whether findings are comparable with the modified scores that include the remaining six food groups consumed in low amounts. The level of significance was set at $\mathrm{p}<0.05$.

\section{RESULTS}

\section{Characteristics}

Compared with all participants with low scores on the hPDI, total participants with high hPDI scores were older, mostly women, more educated, mostly omnivorous and less likely to smoke; with higher urinary excretion of potassium and lower urinary excretion of sodium while participants with high uPDI scores were younger, mostly men, less educated and more likely to smoke; urinary excretion of sodium was higher, while potassium excretion was lower, had lower intakes of protein and dietary fibre and higher intake of carbohydrate compared with participants with low uPDI scores (online supplementary tables S2).

Compared with Western participants with lower hPDI scores, those with higher hPDI scores had lower systolic and diastolic BP, lower BMI, lower intakes of energy and saturated fat and higher intakes of carbohydrates and dietary fibre (online supplementary table S3).

Compared with East Asian participants with lower hPDI scores, participants with higher scores were mostly women, more educated, less likely to smoke; had lower urinary excretion of sodium and higher urinary excretion of potassium (online supplementary table S4).

The nutrient composition of the score in Western and East Asian participants showed higher hPDI scores were lower in trans-fatty acids and dietary cholesterol, and higher in dietary beta-carotene, calcium, iron, magnesium, phosphorus, potassium, retinol, vitamin E, vitamin A, vitamin C compared with lower hPDI scores, while higher uPDI scores were lower in the aforementioned nutrients in comparison with lower uPDI scores (online supplementary tables S3 and S4).

The partial correlation between hPDI and uPDI was -0.3 , while the correlation of overall PDI with hPDI was 0.6 and with uPDI was -0.2 . Univariate estimates of the reliability of $\mathrm{BP}$ measurement were $\geq 90 \%$. Based on the average of two indices, reliability estimates for PDI, hPDI and uPDI for East Asian participants were 65\%, 65\% and $66 \%$, respectively, and for Western participants $69 \%$, $67 \%$ and $67 \%$, respectively. We detected no evidence of potential effect modification by age, sex, smoking, ethnic group, physical activity, BMI or family history of CHD using stratified analyses and interaction terms. Additionally, no cross-country heterogeneity was detected.

\section{Associations of PDI and hPDI with BP}

A six-point higher score of eating a PDI was not associated with $\mathrm{BP}$ after adjusting for lifestyle and dietary factors (model 2; table 1). A six-point higher score of an hPDI, however, was associated with a $-0.82 \mathrm{~mm} \mathrm{Hg}$ lower systolic BP (95\% CI: -1.32 to -0.49 ) and a $-0.49 \mathrm{~mm} \mathrm{Hg}$ lower diastolic BP (95\% CI: -0.91 to 0.28 ) after adjustment for lifestyle and dietary factors. Results were independent of BMI and urinary excretion of sodium and potassium. Additional adjustment for scores of individual healthy food group consumption showed attenuated associations between hPDI and BP with vegetables and whole grains only.

\section{Associations of UPDI with BP}

A six-point higher uPDI score was associated with $+0.77 \mathrm{~mm} \mathrm{Hg}$ higher systolic BP (95\% CI: 0.30 to 1.20 ). For diastolic BP, uPDI score higher by $1 \mathrm{SD}$ was associated with a higher diastolic BP in Western participants only ( $0.48 \mathrm{~mm} \mathrm{Hg} ; 95 \%$ CI: 0.14 to 0.93$)$. Results for systolic and diastolic BP were independent of BMI and urinary excretion of sodium and potassium. Additional adjustment for the individual unhealthy food groups showed attenuated associations between uPDI and BP for intakes of refined grains, sugar-sweetened beverages and total meat (table 1).

\section{Associations of $\mathrm{hPDI}$ and $\mathrm{uPDI}$ with BP in subcohorts}

We repeated the regression analyses in subcohorts after excluding participants with characteristics that might bias associations with BP: excluding those with self-reported diagnosed hypertension, use of antihypertensive drugs, hypertension and major chronic diseases (prevalent cardiovascular diseases and diabetes mellitus) (table 2). In these subcohorts, associations of hPDI and UPDI with systolic BP were consistent with main findings and were independent of BMI and urinary excretion of sodium and potassium. Associations of uPDI with diastolic BP, however, were attenuated. We also repeated the analysis in a subcohort of only users of antihypertensive drugs and found that associations of hPDI and uPDI with systolic $\mathrm{BP}$ were consistent with main results; however, the associations between hPDI and uPDI and BP were attenuated. Additionally, we performed sensitivity analysis by repeating the analysis using scores based on the 12 food groups that were consumed in all countries. This showed consistent associations of hPDI and uPDI with systolic and diastolic BP compared with our main findings (table 2).

\section{DISCUSSION}

In this diverse population-based study, higher adherence to a hPDI, a measure of a high-quality plant-based diet, but not overall PDI, was inversely associated with systolic and diastolic BP. In contrast, a higher score of uPDI was directly associated with systolic BP.

Most participants in the present study were omnivorous (consume animal and plant foods). This suggests that for health benefits, a healthy plant-based diet does not have to be vegan (excluding meat, fish, dairy and eggs) or vegetarian (including eggs or dairy, but excluding meat); however, fewer animal-based foods should be consumed. Further investigation showed that specific food groups altered associations with PDI scores; intakes of vegetables 
Table 1 Estimated mean differences in BP associated with a six-point (1 SD) higher score of PDI, hPDI and uPDI in all INTERMAP participants and stratified by Western and East Asian participants $†$

\section{Systolic blood pressure $(\mathrm{mm} \mathrm{Hg})$ \\ Difference $(95 \% \mathrm{Cl})$}

PDI

All $(n=4680)$

\begin{tabular}{|c|c|c|}
\hline Model 1 & $-1.29(-1.92 \text { to }-0.66)^{\star \star \star}$ & $-0.72(-1.15 \text { to }-0.29)^{\star \star}$ \\
\hline Model 2 & $-0.40(-1.01$ to 0.22$)$ & $-0.34(-0.76$ to 0.09$)$ \\
\hline Model 3a & $-0.02(-0.57$ to 0.61$)$ & $-0.11(-0.53$ to 0.31$)$ \\
\hline Model 3c & $-0.35(-0.96$ to 0.27$)$ & $-0.32(-0.75$ to 0.11$)$ \\
\hline \multicolumn{3}{|c|}{ Western (n=2696) } \\
\hline Model 3a & $-0.09(-0.65$ to 0.83$)$ & $-0.02(-0.50$ to 0.53$)$ \\
\hline Model 3b & $-0.43(-1.19$ to 0.33$)$ & $-0.27(-0.79$ to 0.26$)$ \\
\hline Model 3c & $-0.44(-1.20$ to 0.32$)$ & $-0.26(-0.78$ to 0.27$)$ \\
\hline \multicolumn{3}{|c|}{ East Asian ( $n=1984)$} \\
\hline Model 3b & $-0.26(-1.30$ to 0.78$)$ & $-0.46(-1.20$ to 0.28$)$ \\
\hline Model 3c & $-0.18(-1.23$ to 0.86$)$ & $-0.44(-1.18$ to 0.31$)$ \\
\hline \multicolumn{3}{|l|}{ hPDI } \\
\hline \multicolumn{3}{|l|}{ All } \\
\hline Model 1 & $-1.04(-1.65 \text { to }-0.43)^{\star \star}$ & $-0.62(-1.04 \text { to }-0.21)^{\star \star}$ \\
\hline Model 2 & $-0.82(-1.32 \text { to }-0.49)^{\star \star}$ & $-0.49(-0.91 \text { to }-0.28)^{\star}$ \\
\hline Model 3a & $-0.71(-1.37 \text { to }-0.35)^{\star \star}$ & $-0.42(-0.73 \text { to }-0.29)^{\star}$ \\
\hline Model 3b & $-0.75(-1.36 \text { to }-0.35)^{\star \star}$ & $-0.50(-0.92 \text { to }-0.28)^{\star}$ \\
\hline Model 3a & $-0.83(-1.24 \text { to }-0.67)^{\star \star}$ & $-0.54(-0.89 \text { to } 0.29)^{\star}$ \\
\hline Model 3b & $-0.95(-1.37 \text { to }-0.62)^{\star *}$ & $-0.60(-1.10 \text { to }-0.20)^{\star}$ \\
\hline Model 3c & $-0.58(-1.51 \text { to }-0.14)^{\star}$ & $-0.51(-1.02 \text { to }-0.09)^{\star}$ \\
\hline Model 3d & $-0.49(-1.24$ to 0.08$)$ & $-0.51(-0.96$ to -0.06$)$ \\
\hline Model 3e & $-0.43(-1.09$ to 0.23$)$ & $-0.38(-0.84$ to 0.07$)$ \\
\hline \multicolumn{3}{|c|}{ East Asian $(n=1984)$} \\
\hline Model 1 & $-1.13(-2.34 \text { to } 0.99)^{\star \star}$ & $-0.21(-0.82$ to 0.79$)$ \\
\hline Model 2 & $-0.73(-1.43 \text { to }-0.38)^{*}$ & $-0.29(-1.07$ to 0.49$)$ \\
\hline Model 3a & $-0.51(-1.17 \text { to }-0.25)^{*}$ & $-0.14(-0.89$ to 0.60$)$ \\
\hline Model 3b & $-0.50(-1.40 \text { to }-0.21)^{*}$ & $-0.27(-1.04$ to 0.51$)$ \\
\hline Model 3c & $-0.38(-1.41 \text { to }-0.20)^{*}$ & $-0.31(-1.11$ to 0.48$)$ \\
\hline Model 3d & $-0.24(-0.63$ to 1.10$)$ & $-0.01(-0.60$ to 0.59$)$ \\
\hline
\end{tabular}


Table 1 Continued

\begin{tabular}{l} 
Systolic blood pressure $(\mathrm{mm} \mathrm{Hg})$ \\
\hline Difference $(95 \% \mathrm{Cl})$
\end{tabular}

Model 3e uPDI

All

\begin{tabular}{|c|c|c|}
\hline Model 1 & $0.87(0.21 \text { to } 1.42)^{\star *}$ & $0.34(-0.04$ to 0.72$)$ \\
\hline Model 2 & $0.77(0.30 \text { to } 1.20)^{\star *}$ & $0.24(-0.13$ to 0.61$)$ \\
\hline Model 3a & $0.74(0.28 \text { to } 1.25)^{\star \star}$ & $0.24(-0.12$ to 0.60$)$ \\
\hline Model 3c & $0.55(0.21 \text { to } 1.11)^{*}$ & $0.17(-0.22$ to 0.56$)$ \\
\hline Model $3 f$ & $0.38(-0.10$ to 0.86$)$ & $0.16(-0.18$ to 0.49$)$ \\
\hline Model 3hour & $0.55(-0.06$ to 1.03$)$ & $0.17(-0.17$ to 0.50$)$ \\
\hline \multicolumn{3}{|c|}{ Western $(n=2696)$} \\
\hline Model 1 & $1.33(0.65 \text { to } 2.01)^{\star \star}$ & $0.72(0.27 \text { to } 1.18)^{\star \star}$ \\
\hline Model 2 & $1.00(0.35 \text { to } 1.66)^{\star \star}$ & $0.48(0.14 \text { to } 0.93)^{\star}$ \\
\hline Model 3a & $0.87(0.33 \text { to } 1.51)^{\star \star}$ & $0.41(0.11 \text { to } 0.86)^{\star}$ \\
\hline Model 3g & $0.03(-0.67$ to 0.60$)$ & $0.00(-0.44$ to 0.44$)$ \\
\hline Model 3 hour & $0.55(-0.06$ to 1.16$)$ & $0.27(-0.15$ to 0.69$)$ \\
\hline \multicolumn{3}{|c|}{ East Asian (n=1984) } \\
\hline Model 1 & $0.76(0.58 \text { to } 1.21)^{\star \star}$ & $0.49(-1.16$ to 0.18$)$ \\
\hline Model 2 & $0.81(0.42 \text { to } 1.18)^{\star}$ & $0.27(-0.92$ to 0.39$)$ \\
\hline Model 3a & $0.84(0.35 \text { to } 1.08)^{*}$ & $0.11(-0.73$ to 0.52$)$ \\
\hline Model 3b & $0.66(0.32 \text { to } 0.98)^{*}$ & $0.24(-0.90$ to 0.41$)$ \\
\hline Model 3c & $0.44(0.18 \text { to } 0.94)^{*}$ & $0.25(-0.93$ to 0.43$)$ \\
\hline
\end{tabular}

Values are presented as mean $(95 \% \mathrm{Cl})$; ${ }^{\star} \mathrm{P}<0.05$; ${ }^{\star \star} \mathrm{P}<0.01$; ${ }^{\star \star \star} \mathrm{P}<0.0001$.

†Model 1 is adjusted for sample, age and sex. Model 2 is model 1 adjusted for moderate or heavy physical activity, dietary supplement intake, 7-day alcohol intake, smoking status, total energy intake, history of cardiovascular diseases or diabetes mellitus, family history of hypertension, education level, use of antihypertensive, cardiovascular diseases or diabetes medication and adherence to special diet; model $3 \mathrm{a}$ is model 2 adjusted for BMI; model $3 \mathrm{~b}$ is model 2 adjusted for urinary sodium; model $3 \mathrm{c}$ is model 2 adjusted for urinary potassium, model $3 \mathrm{~d}$ is model 2 adjusted for intakes of vegetables and 'sum of food groups other than vegetables', model 3e is model 2 adjusted for intake of whole grains and 'sum of food groups other than whole grains', model $3 \mathrm{f}$ is model 2 adjusted for intake of refined grains and 'sum of food groups other than refined grains', model $3 \mathrm{~g}$ is model 2 adjusted for sugar-sweetened beverages and 'sum of food groups other than sugarsweetened beverages', model 3 hour is model 2 adjusted for total meat and 'sum of food groups other than total meat'. 1 SD, higher score of 6 for PDI, hPDI, uPDI.

hPDI, healthful PDI; INTERMAP, INTERnational study on MAcro/micronutrients and blood Pressure; PDI, plant-based diet index; uPDI, unhealthful PDI.

and whole grains explained the inverse associations of hPDI with BP, while intakes of refined grains, sugarsweetened beverages and total meat contributed to the direct associations of uPDI with BP.

The availability of detailed repeated multipass 24 hours dietary recall data, compared with food frequency questionnaires, enabled modification of the PDI previously developed by Satija $e t a l^{7}$ to generalise findings between populations with large differences in eating patterns. Country-specific cut-offs were used to score participants with highest consumption, and we limited the maximum score of food groups with low average consumption in one or more populations to avoid overestimation of the score. The consistent findings of stratified analyses by 
Table 2 Estimated mean differences in BP associated with a six-point higher score of hPDI and uPDI in subcohorts of INTERMAP participants $\dagger$

$\begin{array}{lll}\text { Systolic blood pressure }(\mathrm{mm} \mathrm{Hg}) & & \text { Diastolic blood pressure }(\mathrm{mm} \mathrm{Hg}) \\ \text { Difference }(95 \% \mathrm{Cl}) & \text { Difference }(95 \% \mathrm{Cl})\end{array}$

\section{hPDI}

Excluding participants with self-reported diagnosis of hypertension and users of antihypertensive drugsł

\begin{tabular}{|lll}
\hline Model 3a & $-0.63(-1.30 \text { to }-0.40)^{\star \star}$ & $-0.36(-0.54 \text { to }-0.22)^{\star}$ \\
\hline Model 3b & $-0.65(-1.30 \text { to }-0.33)^{\star \star}$ & $-0.41(-0.81 \text { to }-0.26)^{\star}$ \\
\hline Model 3c & $-0.41(-1.00 \text { to }-0.11)^{\star}$ & $-0.33(-0.71 \text { to }-0.11)^{\star}$ \\
\hline Excluding hypertensive participants§ & & \\
\hline Model 3a & $-0.66(-1.28 \text { to }-0.36)^{\star \star}$ & $-0.31(-0.53 \text { to }-0.20)^{\star}$ \\
\hline Model 3b & $-0.62(-1.28 \text { to }-0.31)^{\star \star}$ & $-0.35(-0.82 \text { to }-0.23)^{\star}$ \\
\hline Model 3c & $-0.40(-0.99 \text { to }-0.13)^{\star}$ & $-0.30(-0.68 \text { to }-0.12)^{\star}$
\end{tabular}

Further exclusion of participants with prevalent cardiovascular diseases and diabetes mellitus

\begin{tabular}{|c|c|c|}
\hline Model 3a & $-0.59(-1.25 \text { to }-0.32)^{\star \star}$ & $-0.29(-0.50 \text { to }-0.19)^{*}$ \\
\hline Model 3b & $-0.60(-1.22 \text { to }-0.30)^{\star *}$ & $-0.33(-0.80 \text { to }-0.20)^{*}$ \\
\hline Model 3c & $-0.38(-0.97 \text { to }-0.10)^{*}$ & $-0.29(-0.65 \text { to }-0.11)^{\star}$ \\
\hline \multicolumn{3}{|c|}{ Participants on antihypertensive drugs $† \dagger$} \\
\hline Model 3a & $-0.69(-1.86 \text { to }-0.16)^{\star \star}$ & $-0.42(-0.83 \text { to }-0.22)^{*}$ \\
\hline Model 3b & $-0.64(-1.88 \text { to }-0.24)^{\star \star}$ & $-0.45(-0.89 \text { to }-0.24)^{\star}$ \\
\hline Model 3c & $-0.48(-1.13 \text { to }-0.13)^{\star}$ & $-0.37(-0.77 \text { to }-0.11)^{*}$ \\
\hline \multicolumn{3}{|c|}{ Participants diagnosed with diabetes§§ } \\
\hline Model 3a & $-0.13(-2.53$ to 4.18$)$ & $-0.07(-2.51$ to 1.55$)$ \\
\hline \multicolumn{3}{|c|}{ Results for scores based on 12 food groups } \\
\hline Model 3a & $-0.69(-1.28 \text { to }-0.30)^{\star *}$ & $-0.29(-0.62 \text { to }-0.22)^{*}$ \\
\hline Model 3b & $-0.61(-1.32 \text { to }-0.28)^{\star \star}$ & $-0.33(-0.94 \text { to }-0.23)^{\star}$ \\
\hline Model 3c & $-0.54(-1.01 \text { to }-0.11)^{*}$ & $-0.27(-0.68 \text { to }-0.08)^{\star}$ \\
\hline
\end{tabular}
UPDI

Excluding participants with self-reported diagnosis of hypertension and users of antihypertensive drugs $\ddagger$

\begin{tabular}{lll} 
Model 3a & $0.71(0.25 \text { to } 1.22)^{\star \star}$ & $0.20(-0.11$ to 0.57$)$ \\
Model 3b & $0.77(0.28 \text { to } 1.32)^{\star \star}$ & $0.28(-0.07$ to 0.64$)$ \\
Model 3c & $0.51(0.20 \text { to } 1.09)^{\star}$ & $0.15(-0.21$ to 0.54$)$ \\
\hline Excluding hypertensive participants & & \\
Model 3a & $0.69(0.24 \text { to } 1.20)^{\star \star}$ & $0.19(-0.10$ to 0.55$)$ \\
Model 3b & $0.75(0.26 \text { to } 1.30)^{\star *}$ & $0.27(-0.06$ to 0.62$)$ \\
Model 3c & $0.50(0.18 \text { to } 1.04)^{\star}$ & $0.14(-0.20$ to 0.52$)$
\end{tabular}

Further exclusion of participants with prevalent cardiovascular diseases and diabetes mellitus?

\begin{tabular}{|lll|}
\hline Model 3a & $0.68(0.25 \text { to } 1.22)^{\star \star}$ & $0.19(-0.11$ to 0.57$)$ \\
\hline Model 3b & $0.73(0.28 \text { to } 1.32)^{\star \star}$ & $0.23(-0.04$ to 0.62$)$ \\
\hline Model 3c & $0.51(0.23 \text { to } 1.07)^{\star}$ & $0.13(-0.19$ to 0.55$)$ \\
\hline $\begin{array}{l}\text { Participants on antihypertensive drugst† } \\
\text { Model 3a }\end{array}$ & $0.82(0.16 \text { to } 1.52)^{\star \star}$ & $0.14(-0.27$ to 1.29$)$ \\
\hline Model 3b & $0.89(0.18 \text { to } 1.57)^{\star \star}$ & $0.17(-0.29$ to 1.15$)$ \\
\hline Model 3c & $0.41(0.08 \text { to } 1.39)^{\star}$ & $0.11(-0.21$ to 1.24$)$ \\
\hline $\begin{array}{l}\text { Participants diagnosed with diabetes§§ } \\
\text { Model 3a }\end{array}$ & $0.08(-2.63$ to 3.65$)$ & $0.02(-1.99$ to 1.78$)$ \\
\hline
\end{tabular}




\begin{tabular}{|c|c|c|}
\hline & Systolic blood pressure (mm Hg) & Diastolic blood pressure $(\mathrm{mm} \mathrm{Hg})$ \\
\hline & Difference (95\% Cl) & Difference (95\% Cl) \\
\hline Model 3a & $-0.49(-1.25 \text { to }-0.32)^{\star \star}$ & $-0.31(-0.55 \text { to }-0.17)^{\star}$ \\
\hline Model 3c & $-0.25(-0.97 \text { to }-0.10)^{\star}$ & $-0.30(-0.67 \text { to }-0.13)^{\star}$ \\
\hline
\end{tabular}

Values are presented as mean $(95 \% \mathrm{Cl}) ;{ }^{*} \mathrm{P}<0.05 ;{ }^{\star \star} \mathrm{P}<0.01 ;{ }^{\star \star \star} \mathrm{P}<0.0001$.

†Model 2 is adjusted for sample, age, sex, moderate or heavy physical activity, dietary supplement intake, 7-day alcohol intake, smoking status, total calorie intake, history of cardiovascular disease or diabetes mellitus, family history of hypertension, education level, use of antihypertensive, cardiovascular disease or diabetes medication and adherence to special diet. Model $3 a$ is model 2 adjusted for BMl; model $3 \mathrm{~b}$ is model 2 additionally adjusted for urinary sodium; model $3 \mathrm{c}$ is model two adjusted for urinary potassium. $1 \mathrm{SD}=6 \mathrm{for}$ PDI, hPDI, uPDI. ¥Subcohort excluding participants with a self-reported diagnosis of hypertension and users of antihypertensive drugs, $n=3532$.

§Subcohort excluding from foregoing cohort also those with high systolic BP ( $\geq 140 \mathrm{~mm} \mathrm{Hg})$ or diastolic BP $(\geq 90 \mathrm{~mm} \mathrm{Hg}), \mathrm{n}=3363$. IS Subcohort excluding from foregoing cohort also those with prevalent cardiovascular diseases and diabetes, $\mathrm{n}=3051$.

††Subcohort of users of antihypertensive drugs, $n=1148$.

$\ddagger \ddagger$ Subcohort of participants diagnosed with diabetes, $n=277$.

$\S \S R e s u l t s$ for scores based on 12 food groups (fruits, vegetables, legumes, vegetable oils, tea/coffee, refined grains, potatoes, sweets/ desserts, animal fat, eggs, total meat and miscellaneous foods), consumed by all 4680 participants.

BP, blood pressure; hPDI, healthy PDI; INTERMAP, INTERnational study on MAcro/micronutrients and blood Pressure; PDI, plant-based diet index; UPDI, unhealthy PDI.

Western and East Asian participants and sensitivity analysis using scores based on 12 food groups consumed by all participants confirmed robustness of the modified PDI.

To our knowledge, this is the first study that investigated the influence of healthiness on the association between plant-based diets and BP. Results of a meta-analyses of six randomised controlled clinical trials and 32 observational studies showed that participants who adhered to a vegan or vegetarian diet had a lower BP or lower prevalence of hypertension compared with those eating an omnivorous diet. However, inconsistent results were found in a recent meta-analyses of nine randomised controlled trials. ${ }^{1}$ Although evidence is well established on the higher risk of hypertension of consuming less healthy plant foods, like refined grains and sugar-sweetened beverages, ${ }^{20} 21$ most studies have so far failed to consider this in their investigation on the impact of plant-based diets on health. Findings of the present study showed that consumption of a healthy plant-based diet was directly associated with $\mathrm{BP}$ as opposed to a less healthy plant-based diet. Sensitivity analyses of only users of antihypertensive drugs, and subcohorts excluding participants with health conditions that might bias associations of hPDI and uPDI with BP showed that significant findings prevailed. These findings suggest that healthiness of a plant-based diet may influence associations with BP and should be taken into account in future research.

Our results for uPDI were slightly attenuated in East Asian participants compared with Western participants. The different dietary and lifestyle patterns in these two samples might explain this. Of those who scored higher on the uPDI, East Asian participants consumed larger amounts of refined grains and lower amounts of dietary fibre than Western participants. These findings are comparable to results of the National Japanese survey where rice consumption accounted for $\sim 30 \%$ of total energy intake, ${ }^{24}$ and was a large contributor to the diet in the Shanghai Women's Health Study ${ }^{25}$ In addition, a large national survey comparing nutrient intakes across Chinese, Japanese and American populations showed that Chinese and Japanese diets had lower daily intakes of fibre compared with American diets. ${ }^{26}$

Our findings suggest that intakes of vegetables and whole grains were drivers of the inverse associations of hPDI with BP. Our results show that eating one serving of whole grains and four servings of vegetables, while limiting total meat intake to $100 \mathrm{~g}$ per day was associated with a systolic BP lower by $\sim 4 \mathrm{~mm} \mathrm{Hg}$. Earlier results from the INTERMAP showed significant inverse relationships between vegetable protein and BP in contrast to animal protein intake ${ }^{27}$ and of especially raw vegetables $^{28}$ and dietary fibre ${ }^{29}$ with BP. A previous metaanalysis of 28 prospective cohort studies showed that a daily intake of $30 \mathrm{~g}$ whole grains was associated with $8 \%$ lower risk of hypertension. ${ }^{30}$ Findings of our study also suggest that refined grains, sugar-sweetened beverages and total meat consumption contributed to the direct associations of uPDI with BP. Previous results from the INTERMAP showed direct associations with BP of sugar and sugar-sweetened beverages ${ }^{31}$ and with unprocessed and processed red meat. ${ }^{32}$

The mechanism by which a hPDI may influence BP may be due to the unique food matrix of a plant-based diet which is rich in nutrients that may work synergistically to lower BP. ${ }^{33}$ The landmark Dietary Approaches to Stop Hypertension (DASH) Trial was first to show reductions in diastolic and systolic $\mathrm{BP}$ when adhering to DASH, a diet with plenty of vegetables, fruits and low-fat dairy products but restricted in sodium, total and saturated fats. ${ }^{34}$ BP-lowering effects could be due to the low animal-based content, the various arrays of nutrients and micronutrients present in vegetables and whole grains, including dietary fibre, ${ }^{35}$ potassium, ${ }^{36}$ calcium $^{37}$ and unsaturated fatty acids may improve vascular endothelial 
function. ${ }^{38}$ Further analysis into the nutrient composition of the scores found that nutrients such as (calcium, iron, magnesium, phosphorus, potassium and vitamin $\mathrm{C}$ ) were higher, while trans-fatty acids, dietary cholesterol and sodium were lower in the higher hPDI compared with the lower hPDI score. The high potassium and low sodium content of a healthy plant-based diet may affect the renin-angiotensin system by reducing angiotensin influences on receptors and improving fluid regulatory hormones. $^{39}$

A major limitation of the present study is its crosssectional design; we were not able to make inferences on long-term causality. Although we were able to account for several confounding factors, residual confounding, such as by inaccurate measurement of physical activity and reporting bias, which dietary recalls are subject to, cannot be ruled out. Another limitation is that we used robust standardised food groups based on the standardised USDA food groups, thus some specific food groups known to be beneficial for BP, for example, dark chocolate, ${ }^{40}$ low fat dairy ${ }^{41}$ received adverse scores. Future research may need more refined classification of food groups.

Findings of the present cross-sectional populationbased study suggest that dietary patterns that are relatively higher in high-quality plant foods, such as vegetables and whole grains, and lower in animal foods; may be beneficial for BP. The fact that most participants were omnivorous indicates that a healthy plant-based diet does not imply being vegan or vegetarian, but preferably consuming moderate amounts of animal-based food can be beneficial. It is important to consider the adverse outcomes associated with low-quality plant foods, such as refined grains and sugar-sweetened beverages, when investigating plant-based diets and BP. Although current guidelines recommend shifting towards a plant-based diet, recommendations should emphasise more on the nutritional quality of plant foods which may be as important as limiting animal-based foods to maintain healthy BP.

\section{Author affiliations}

${ }^{1}$ Department of Community Health Sciences, College of Applied Medical Sciences, King Saud University, Riyadh, Saudi Arabia

${ }^{2}$ Department of Epidemiology and Biostatistics, School of Public Health, Imperial College London, London, UK

${ }^{3} \mathrm{MRC}$ Centre for Environment and Health, Imperial Biomedical Research Centre, Imperial College London, London, UK

${ }^{4}$ Department of Nutritional Sciences, King's College London, London, UK

${ }^{5}$ Department of Preventive Medicine, Northwestern University Feinberg School of Medicine, Chicago, Illinois, USA

${ }^{6}$ College of Medicine, Institute for Minority Health Research, University of Illinois at Chicago, Chicago, Illinois, USA

${ }^{7}$ Department of Public Health, Shiga University of Medical Science, Otsu, Shiga, Japan

${ }^{8}$ Clinical Research Institute and School of Public Health, Peking University, Beijing, Beijing, China

${ }^{9}$ Division of Prevention and Community Health, National Center for Cardiovascular Disease, Fuwai Hospital, Chinese Academy of Medical Sciences and Peking Union Medical College, Beijing, China

${ }^{10}$ NIHR Biomedical Research Centre, Diet, Anthropometry, and Physical Activity Group, MRC Epidemiology Unit, University of Cambridge, Cambridge, UK
Acknowledgements We thank all INTERMAP participants and staff at the local, national and international centres for their invaluable efforts; a partial listing of those colleagues is mentioned in: Holmes E, Loo R, Stamler J, et al. Human metabolic phenotype diversity and its association with diet and blood pressure. Nature. 2008;453:396-400.

Contributors ARD, HU, JS, KM, LZ and PE designed the INTERMAP, conducted the fieldwork and collected data; GA and LMOG performed the analysis, interpreted the data and prepared the manuscript; HU, JS, KM, LVH, LZ, MLD, QC, PE, RG and YW revised the work critically for important intellectual content; GA and LMOG were responsible for final content and all authors: read and approved the final manuscript.

Funding INTERMAP was supported by grants R01-HL50490, R01-HL65461, R01HL84228 and R01-HL135486 from the National Heart, Lung, and Blood Institute, $\mathrm{NIH}$ (Bethesda, MD, USA) and by the Ministry of Education, Culture, Sports, Science, and Technology of Japan (Grant-in-Aid for Scientific Research [A], No. 090357003 and No. 17H01553) and the UK (a project grant from the West Midlands National Health Service Research and Development, and grant R2019EPH from the Chest, Heart and Stroke Association). PE is Director of the MRC Centre for Environment and Health and acknowledges support from the Medical Research Council (MR/ S019669/1). LOG is supported by the NIHR Cambridge Biomedical Research Centre (IS-BRC-1215-20014).

Competing interests None declared.

Patient consent for publication Not required.

Ethics approval Approved by St. Mary's Research Ethics Committee, REC reference number: EC3169. INTERMAP was approved by the Institutional Review Board of Northwestern University (STU00204462-CR0002) and the Research Ethics Committee of the Health Research Authority (UK, \#EC3169).

Provenance and peer review Not commissioned; externally peer reviewed. Data availability statement Data are available upon reasonable request.

Open access This is an open access article distributed in accordance with the Creative Commons Attribution Non Commercial (CC BY-NC 4.0) license, which permits others to distribute, remix, adapt, build upon this work non-commercially, and license their derivative works on different terms, provided the original work is properly cited, appropriate credit is given, any changes made indicated, and the use is non-commercial. See: http://creativecommons.org/licenses/by-nc/4.0/.

ORCID iD

Ghadeer Aljuraiban http://orcid.org/0000-0002-4866-5461

\section{REFERENCES}

1 Viguiliouk E, Kendall CW, Kahleová $\mathrm{H}$, et al. Effect of vegetarian dietary patterns on cardiometabolic risk factors in diabetes: a systematic review and meta-analysis of randomized controlled trials. Clin Nutr 2019;38:1133-45.

2 Hu FB. Plant-Based foods and prevention of cardiovascular disease: an overview. Am J Clin Nutr 2003;78:544S-51.

3 Juraschek SP, Guallar E, Appel LJ, et al. Effects of vitamin C supplementation on blood pressure: a meta-analysis of randomized controlled trials. Am J Clin Nutr 2012;95:1079-88.

4 Filippini T, Violi F, D'Amico R, et al. The effect of potassium supplementation on blood pressure in hypertensive subjects: a systematic review and meta-analysis. Int J Cardiol 2017;230:127-35.

5 USDA, US Department of Health and Human Services. Scientific report of the 2015 dietary guidelines Advisory Committee: Advisory report to the Secretary of health and human services and the Secretary of agriculture. Washington (DC): US department of health and human services, 2015. Https://health.Gov/ dietaryguidelines/2015-scientific-report

6 Yokoyama Y, Nishimura K, Barnard ND, et al. Vegetarian diets and blood pressure: a meta-analysis. JAMA Intern Med 2014;174:577.

7 Satija A, Bhupathiraju SN, Spiegelman D, et al. Healthful and Unhealthful Plant-Based Diets and the Risk of Coronary Heart Disease in U.S. Adults. J Am Coll Cardiol 2017;70:411-22.

8 Stamler J, Elliott P, Dennis B, et al. INTERMAP: background, aims, design, methods, and descriptive statistics (nondietary). J Hum Hypertens 2003;17:591-608.

9 Dennis B, Stamler J, Buzzard M, et al. INTERMAP: the dietary data-process and quality control. J Hum Hypertens 2003;17:609-22.

10 Robertson C, Conway R, Dennis B, et al. Attainment of precision in implementation of $24 \mathrm{H}$ dietary recalls: INTERMAP UK. Br J Nutr 2005;94:588-94. 
11 USDA, agricultural research service, nutrient data laboratory. USDA national nutrient database for standard reference, release 27 . Version current september 2015. Available: Http://www.Ars.Usda.Gov/ba/ bhnrc/ndl [Accessed 10 Mar 2016].

12 Schwingshackl L, Bogensberger B, Benčič A, et al. Effects of oils and solid fats on blood lipids: a systematic review and network metaanalysis. J Lipid Res 2018;59:1771-82.

13 Marventano S, Izquierdo Pulido M, Sánchez-González C, et al. Legume consumption and CVD risk: a systematic review and metaanalysis. Public Health Nutr 2017;20:245-54.

14 Aune D, Giovannucci E, Boffetta P, et al. Fruit and vegetable intake and the risk of cardiovascular disease, total cancer and all-cause mortality-a systematic review and dose-response meta-analysis of prospective studies. Int J Epidemiol 2017;46:1029-56.

15 Zhang B, Zhao Q, Guo W, et al. Association of whole grain intake with all-cause, cardiovascular, and cancer mortality: a systematic review and dose-response meta-analysis from prospective cohort studies. Eur J Clin Nutr 2018;72:57-65.

16 Grosso G, Yang J, Marventano S, et al. Nut consumption on all-cause, cardiovascular, and cancer mortality risk: a systematic review and meta-analysis of epidemiologic studies. Am J Clin Nutr 2015;101:783-93.

17 Zhang C, Qin Y-Y, Wei X, et al. Tea consumption and risk of cardiovascular outcomes and total mortality: a systematic review and meta-analysis of prospective observational studies. Eur J Epidemiol 2015;30:103-13.

18 Gunter MJ, Murphy N, Cross AJ, et al. Coffee drinking and mortality in 10 European countries: a multinational cohort study. Ann Intern Med 2017;167:236-47.

19 Borch D, Juul-Hindsgaul N, Veller M, et al. Potatoes and risk of obesity, type 2 diabetes, and cardiovascular disease in apparently healthy adults: a systematic review of clinical intervention and observational studies. Am J Clin Nutr 2016;104:489-98.

20 Reynolds A, Mann J, Cummings J, et al. Carbohydrate quality and human health: a series of systematic reviews and meta-analyses. Lancet 2019;393:434-45.

21 Jayalath VH, de Souza RJ, Ha V, et al. Sugar-Sweetened beverage consumption and incident hypertension: a systematic review and meta-analysis of prospective cohorts. Am J Clin Nutr 2015;102:914-21.

22 The food and agriculture organization of the United nations. FoodBased dietary guidelines. China, 2016. Available: Http://www.Fao. Org/nutrition/education/food-dietaryguidelines/regions/countries/ china/en

23 Grandits GA, Bartsch GE, Stamler J. Method issues in dietary data analyses in the multiple risk factor intervention trial. Am J Clin Nutr 1997;65:211S-27.

24 Kenko eiyo joho kenkyukai. The National health and nutrition survey in Japan, 2006. Tokyo, Japan: Daiichi-shuppan, 2009.

25 Villegas R, Liu S, Gao Y-T, et al. Prospective study of dietary carbohydrates, glycemic index, glycemic load, and incidence of type 2 diabetes mellitus in middle-aged Chinese women. Arch Intern Med 2007;167:2310-6.
26 Zhang R, Wang Z, Fei Y, et al. The difference in nutrient intakes between Chinese and Mediterranean, Japanese and American diets. Nutrients 2015;7:4661-88

27 Elliott P, Stamler J, Dyer AR, et al. Association between protein intake and blood pressure: the INTERMAP study. Arch Intern Med 2006;166:79-87.

28 Chan Q, Stamler J, Brown IJ, et al. Relation of raw and cooked vegetable consumption to blood pressure: the INTERMAP study. $J$ Hum Hypertens 2014;28:353-9.

29 Aljuraiban GS, Griep LMO, Chan Q, et al. Total, insoluble and soluble dietary fibre intake in relation to blood pressure: the INTERMAP Study - CORRIGENDUM. Br J Nutr 2015;114:1534.

30 Schwingshackl L, Schwedhelm C, Hoffmann G, et al. Food groups and risk of hypertension: a systematic review and dose-response meta-analysis of prospective studies. Adv Nutr 2017;8:793-803.

31 Brown IJ, Stamler J, Van Horn L, et al. Sugar-Sweetened beverage, sugar intake of individuals, and their blood pressure: International study of macro/micronutrients and blood pressure. Hypertension 2011;57:695-701.

32 Oude Griep LM, Seferidi P, Stamler J, et al. Relation of unprocessed, processed red meat and poultry consumption to blood pressure in East Asian and Western adults. $J$ Hypertens 2016;34:1721-9.

33 Jacobs DR, Gross MD, Tapsell LC. Food synergy: an operational concept for understanding nutrition. Am J Clin Nutr 2009;89:1543S-8.

34 Appel LJ, Moore TJ, Obarzanek E, et al. A clinical trial of the effects of dietary patterns on blood pressure. $N$ Engl J Med 1997;336:1117-24.

35 Evans CEL, Greenwood DC, Threapleton DE, et al. Effects of dietary fibre type on blood pressure: a systematic review and meta-analysis of randomized controlled trials of healthy individuals. J Hypertens 2015;33:897-911.

36 Whelton PK, He J, Cutler JA, et al. Effects of oral potassium on blood pressure. meta-analysis of randomized controlled clinical trials. JAMA 1997;277:1624-32.

37 van Mierlo LAJ, Arends LR, Streppel MT, et al. Blood pressure response to calcium supplementation: a meta-analysis of randomized controlled trials. J Hum Hypertens 2006;20:571-80.

38 Miller PE, Van Elswyk M, Alexander DD. Long-Chain omega-3 fatty acids eicosapentaenoic acid and docosahexaenoic acid and blood pressure: a meta-analysis of randomized controlled trials. Am J Hypertens 2014;27:885-96.

39 Engeli S, Boschmann M, Frings $\mathrm{P}$, et al. Influence of salt intake on renin-angiotensin and natriuretic peptide system genes in human adipose tissue. Hypertension 2006;48:1103-8.

40 Desch S, Schmidt J, Kobler D, et al. Effect of cocoa products on blood pressure: systematic review and meta-analysis. Am J Hypertens 2010;23:97-103.

41 Ralston RA, Lee JH, Truby $\mathrm{H}$, et al. A systematic review and metaanalysis of elevated blood pressure and consumption of dairy foods. J Hum Hypertens 2012;26:3-13. 